\title{
Simultaneous Determination of Seven Carbamate Pesticide Residues in Vegetable by Capillary Electrophoresis with Solid Phase Microextraction
}

\author{
Wenjuan Zhang ${ }^{1}$, Fuxiu Yang ${ }^{1}$, Yuan Zhang ${ }^{1,2, *}$, Kaowen Zhou ${ }^{1,2, *}$ \\ ${ }^{1}$ Biochemical Engineering College, Beijing Union University, Beijing 100023, China \\ ${ }^{2}$ Beijing Key Laboratory of Biomass Waste Resource Utilization, Beijing 100023, China \\ *E-mail: zhoukaowen@,buu.edu.cn, zhangyuan333@126.com
}

doi: $10.20964 / 2021.06 .06$

Received: 19 January 2021 / Accepted: 26 March 2021 / Published: 30 April 2021

\begin{abstract}
An efficient method for simultaneous determination of seven carbamate pesticides in vegetable was established based on purifing and enriching by solid phase microextraction, separating by capillary electrophoresis (CE) and detecting by column end electrochemiluminescence (ECL). The effects of acidity, time, temperature, ionic strength and eluent on the recovery of seven pesticides in sample solutions were investigated. The best purification and enrichment parameters of $0.2 \mathrm{~g}$ hollow fiber in $10.0 \mathrm{~mL}$ extraction solution are: $\mathrm{pH}$ value 6 , extraction time $35 \mathrm{~min}$, extraction temperature $50^{\circ} \mathrm{C}, \mathrm{NaCl}$ $1.5 \mathrm{~g}$, and $2.0 \mathrm{~mL}$ acetonitrile (containing 5\% formic acid) as eluent. The effects of acidity, salt concentration, additive concentration and separation voltage on the resolution of seven pesticides in separation medium were investigated. The phosphate buffer solution (PBS) containing $45 \mathrm{mmol} / \mathrm{L} \mathrm{NaCl}$ and $25 \mathrm{mmol} / \mathrm{L}$ cyclodextrin was used as separation solution of CE. The $\mathrm{pH}$ of PBS is 6.5. The separation voltage is $17 \mathrm{kV}$. There are good linear relationships between the mass concentrations of seven carbamate pesticides and their ECL intensities. Their detection limits were $0.1-0.5 \mu \mathrm{g} / \mathrm{L}$. The recoveries of standard addition for vegetable samples were $86.1 \%-115.8 \%$. The method is rapid and accurate for the determination of carbamate pesticides in vegetables.
\end{abstract}

Keywords: Carbamate pesticide, Vegetable, Solid phase microextraction, Capillary electrophoresis

\section{FULL TEXT}

(C) 2021 The Authors. Published by ESG (www.electrochemsci.org). This article is an open access article distributed under the terms and conditions of the Creative Commons Attribution license (http://creativecommons.org/licenses/by/4.0/). 